Article

\title{
Breathing 3D Frameworks with T-Shaped Connecting Ligand Exhibiting Solvent Induction, Metal Ions Effect and Luminescent Properties
}

\author{
Yong-Cong $\mathrm{Ou}$ *, Ying-Yi Song, Hui-Ming Du, Meng-Meng Hao and Jian-Zhong Wu * \\ Guangzhou Key Laboratory of Materials for Energy Conversion and Storage, \\ School of Chemistry and Environment, South China Normal University, Guangzhou 510006, China; \\ 20132401121@m.scnu.edu.cn (Y.-Y.S.); 20142401129@m.scnu.edu.cn (H.-M.D.); \\ 20142401134@m.scnu.edu.cn (M.-M.H.) \\ * Correspondence: ouyongcong@m.scnu.edu.cn (Y.-C.O.); wujzh@scnu.edu.cn (J.-Z.W.) \\ Academic Editor: Dmitriy V Soldatov \\ Received: 18 August 2017; Accepted: 13 October 2017; Published: 17 October 2017
}

\begin{abstract}
To study the structural effects in three-dimensional porous coordination polymers, three novel flexible porous coordination polymers- $\left[\mathrm{Cd}_{2}(\mathrm{bpdc})_{2}\right](\mathrm{DMF})_{3}\left(\mathrm{H}_{2} \mathrm{O}\right)(\mathbf{1})$ and $[\mathrm{M}(\mathrm{bpdc})](\mathrm{DMF})\left(\mathrm{H}_{2} \mathrm{O}\right)$ $(\mathrm{M}=\mathrm{Cd}(2), \mathrm{Zn}(3))$ - have been synthesized under solvothermal conditions with $\mathrm{d}^{10}$ block metal ions and T-shaped connecting ligand. Complexes 1-3 crystallize in different space groups, but they display the same ant network. The first two complexes can transform into each other via the alteration of guest, whereas complex 3 shows no structural change. The structural details reveal that the size of metal ions might be responsible for the transformation of porous frameworks. Furthermore, luminescent properties have been explored, and a guest-dependent shift of emission peaks was observed, suggesting potential application of the complexes as a probe.
\end{abstract}

Keywords: porous framework; breathing effect; solvent induction; luminescence

\section{Introduction}

The rational design and synthesis of porous coordination polymers (PCPs) and metal-organic frameworks (MOFs) have attracted a great deal of attention for more than two decades thanks to possibility of their structure regulation and potential applications in gas storage and separation [1-4], catalysis [5-8], magnetism [9,10], sensing [11-13], drug delivery [14,15], and so on [16]. The framework structures of PCPs/MOFs could depend on the type of metal ions, organic ligands, and the solvent used. Recently, breathing effects became of interest to solid-state chemists and physicists in the context of the flexibility and phase transitions of the frameworks $[17,18]$. Flexible PCPs were reported less frequently since the materials may become unstable when the coordination bonds and/or weak supramolecular interactions are changed. Flexible frameworks were assembled through flexible carboxylate ligands in our previous work [19], and it is of great importance for us to deepen the strategy to the construction with rigid ligands. Another reason for choosing rigid ligands is that the construction and regulation of PCPs becomes simplified.

The multidentate ligand 2,2'-bipyridine-5,5'-dicarboxylic acid $\left(\mathrm{H}_{2} \mathrm{bpdc}\right)$ is a good candidate because it contains two types of coordination groups-carboxylate groups and chelating position $\mathrm{N}$-donors-which can act in linear bridging mode and/or T-shaped connecting mode [20-37]. To date, there are 20 different coordination modes for $\mathrm{H}_{2}$ bpdc ligand observed in the structures retrieved from the Cambridge Structural Database (CSD version 5.38, February 2017) [38] (Figure 1, Scheme S1). Among those, type b usually results in zero dimensional molecular complexes, as it only acts as a chelating ligand via $\mathrm{N}$-donors from the bipyridine [28]. To construct 3D flexible PCPs, although type a (T-shaped connecting mode) is reported 
more frequently, type c (linear bridging mode) is the most favorable option because the bpdc ${ }^{2-}$ ligands in the former type often act essentially as rigid spacers [20-23]. Besides that, auxiliary ligands were also introduced to tune the flexibility of the frameworks [24]. It is interesting that there are relatively fewer reports on the flexible PCPs that are constructed with homometallic ions and pure $\mathrm{H}_{2}$ bpdc ligand as T-shaped connecting modes, especially in type a [25].

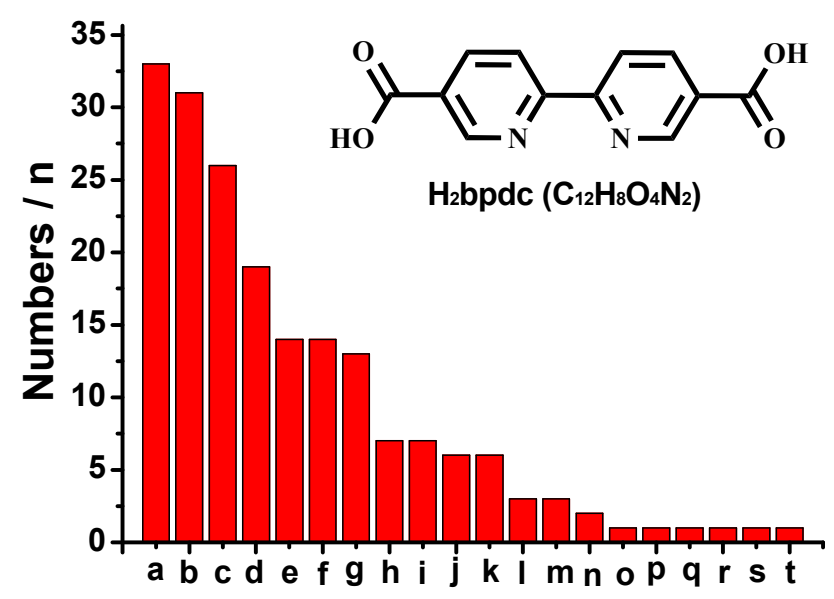

Figure 1. The number of published structures which contain $\mathrm{H}_{2}$ bpdc ligands in different coordination modes. a-t represent the types of coordination modes, see Scheme S1.

\section{Experimental}

\subsection{Materials and Physical Measurements}

The reagents and solvents were commercially available and used as received without further purification. C, H, and N microanalyses were carried out with Elementar Vario-EL CHN elemental analyzer. Powder X-ray diffraction (PXRD) intensities for polycrystalline samples of 1-3 and solvent soaking samples were measured at $293 \mathrm{~K}$ on a Bruker D8 Advance Diffractometer $(\mathrm{CuK} \alpha$, $\lambda=1.54056 \AA$ ) by scanning over the range of $5^{\circ}-50^{\circ}$ with step of $0.2^{\circ} / \mathrm{s}$. Simulated PXRD patterns of 1-3 were generated with Mercury software. Fourier transform infrared (FT-IR) spectra were recorded with $\mathrm{KBr}$ tablets in the range $4000-400 \mathrm{~cm}^{-1}$ on Perkin Elmer Spectrum One spectrometer. Thermogravimetric (TG) analysis was carried out on NETZSCH TG209F3 (NETZSCH, Bavaria, Germany) thermogravimetric analyzer. Nitrogen gas sorption isotherms for activated sample of 1 were measured on a volumetric adsorption apparatus (Bel-max, Osaka, Japan). The fluorescent spectra of solid samples of 1-3 were measured on Hitachi F-4600 at room temperature with a xenon arc lamp as the light source.

\section{2. $\left[C d_{2}(b p d c)_{2}\right](D M F)_{3}\left(H_{2} \mathrm{O}\right)$}

(1): A mixture of $\mathrm{CdCl}_{2} \cdot 0.5 \mathrm{H}_{2} \mathrm{O}(0.2 \mathrm{mmol}, 46 \mathrm{mg}), \mathrm{H}_{2}$ bpdc $(0.2 \mathrm{mmol}, 48 \mathrm{mg})$, and DMF (15.0 mL) was put in a stainless steel reactor with Teflon liner $(23 \mathrm{~mL})$ at ambient temperature for a week, and then heated at $120^{\circ} \mathrm{C}$ for $72 \mathrm{~h}$ and cooled to ambient temperature at a rate of ca. $3^{\circ} \mathrm{C} \cdot \mathrm{h}^{-1}$ to give colorless block crystals (yields based on $\mathrm{H}_{2}$ bpdc: $80 \mathrm{mg}$, $84.5 \%$ ). Elemental analysis calculated for $\mathrm{C}_{33} \mathrm{H}_{35} \mathrm{~N}_{7} \mathrm{O}_{12} \mathrm{Cd}_{2}$ (\%): C 41.88, H 3.73, N 10.36; found (\%): C 42.02, H 3.74, N 10.44.

\section{3. $[\mathrm{Cd}(b p d c)](\mathrm{DMF})\left(\mathrm{H}_{2} \mathrm{O}\right)$}

(2): Similar method as $\mathbf{1}$ except the solvent was replaced by a mixture solvent, DMF: $\mathrm{H}_{2} \mathrm{O}=1: 1$. Colorless block crystals were obtained (yields based on $\mathrm{H}_{2}$ bpdc: $24 \mathrm{mg}, 26.9 \%$ ). Elemental analysis calculated for $\mathrm{C}_{15} \mathrm{H}_{15} \mathrm{~N}_{3} \mathrm{O}_{6} \mathrm{Cd}(\%)$ : C 40.42, H 3.39, N 9.43; found (\%): C 40.21, H 3.14, N 9.44. 


\section{4. $[\mathrm{Zn}(b p d c)](\mathrm{DMF})\left(\mathrm{H}_{2} \mathrm{O}\right)$}

(3): A mixture of $\mathrm{ZnSO}_{4} \cdot 7 \mathrm{H}_{2} \mathrm{O}(0.2 \mathrm{mmol}, 56 \mathrm{mg})$ and $\mathrm{H}_{2}$ bpdc $(0.2 \mathrm{mmol}, 48 \mathrm{mg})$ was dissolved in DMF $(12 \mathrm{~mL})$, and adjusted to the $\mathrm{pH}$ value of ca. 8 with hexamethylenetetramine. After standing for one week in a stainless steel reactor with Teflon liner $(23 \mathrm{~mL})$ at ambient temperature, the mixture was heated at $120{ }^{\circ} \mathrm{C}$ for $72 \mathrm{~h}$ and cooled to ambient temperature at the rate of ca. $3^{\circ} \mathrm{C} \cdot \mathrm{h}^{-1}$ to give light yellow block crystals (yields based on $\mathrm{H}_{2}$ bpdc: $30 \mathrm{mg}$, $75.2 \%$ ). Elemental analysis calculated for $\mathrm{C}_{15} \mathrm{H}_{15} \mathrm{~N}_{3} \mathrm{O}_{6} \mathrm{Zn}(\%)$ : C 45.19, H 3.79, N 10.54; found (\%): C 45.48, H 3.81, N 10.37.

\subsection{X-ray Crystallography}

Complexes 1-3 were sealed in a quartz tube with DMF solution and the diffraction data for 1-3 were collected on Oxford Diffraction Xcalibur Nova with $\mathrm{Cu}-\mathrm{K} \alpha$ radiation $(\lambda=1.54184 \AA$ ) at 293(2) K, Bruker D8 QUEST diffractometer with MoK $\alpha$ radiation $(\lambda=0.71073 \AA)$ at 293(2) K and Bruker Apex II $\mathrm{CCD}$ area detector diffractometer (MoK $\alpha$ radiation) at 296(2) $\mathrm{K}$, respectively. Absorption corrections were applied by using multiscan program SADABS. The structures were solved using direct methods and refined using the SHELXTL program [39]. For complexes 2 and 3, the disorder of DMF and $\mathrm{H}_{2} \mathrm{O}$ molecules could not be modelled properly, hence the program SQUEEZE [40]—a part of the PLATON package of crystallographic software-was used to calculate the disordered solvent contribution and remove it from the overall intensity data. Further details of the structural analysis for complexes 1-3 are summarized in Table 1.

Table 1. Crystal data and structure refinements for 1-3.

\begin{tabular}{|c|c|c|c|}
\hline Complex & $1(293 \mathrm{~K})$ & $2(293 \mathrm{~K})$ & $3(296 \mathrm{~K})$ \\
\hline $\begin{array}{l}\text { Empirical formula } \\
\qquad \mathrm{fw}\end{array}$ & $\begin{array}{c}\mathrm{C}_{33} \mathrm{H}_{35} \mathrm{~N}_{7} \mathrm{O}_{12} \mathrm{Cd}_{2} \\
946.48\end{array}$ & $\begin{array}{c}\mathrm{C}_{15} \mathrm{H}_{15} \mathrm{~N}_{3} \mathrm{O}_{6} \mathrm{Cd} \\
445.70\end{array}$ & $\begin{array}{c}\mathrm{C}_{15} \mathrm{H}_{15} \mathrm{~N}_{3} \mathrm{O}_{6} \mathrm{Zn} \\
398.67\end{array}$ \\
\hline Crystal system & Monoclinic & Orthorhombic & Orthorhombic \\
\hline Space group & $P 2_{1} / c$ & Fddd & Fddd \\
\hline$a / \AA$ & $11.8988(2)$ & $17.4483(5)$ & $15.930(7)$ \\
\hline$b / \AA$ & $24.8683(4)$ & $19.4148(6)$ & $19.280(8)$ \\
\hline$c / \AA$ & $12.8119(2)$ & $23.8529(7)$ & $23.109(9)$ \\
\hline$\beta /^{\circ}$ & $93.0640(10)$ & 90 & 90 \\
\hline $\mathrm{V} / \AA^{3}$ & $3785.66(11)$ & $8080.3(4)$ & $7097(5)$ \\
\hline Z & 4 & 16 & 16 \\
\hline$\rho_{\text {calcd }} / \mathrm{g} \mathrm{cm}^{-3}$ & 1.661 & 1.465 & 1.492 \\
\hline$\mu / \mathrm{mm}^{-1}$ & 9.599 & 1.112 & 1.419 \\
\hline S & 1.059 & 1.070 & 1.017 \\
\hline$R_{1}{ }^{[\mathrm{a}]}, w R_{2}{ }^{[\mathrm{b}]}(I>2 \sigma(I))$ & $0.0407,0.0993$ & 0.0313(SQUEEZE), 0.0825(SQUEEZE) & 0.0589(SQUEEZE), 0.1563(SQUEEZE) \\
\hline$R_{1}{ }^{[\mathrm{a}]}, w R_{2}{ }^{[\mathrm{b}]}$ (all data) & $0.0561,0.1104$ & 0.0375(SQUEEZE), 0.0873(SQUEEZE) & 0.0900(SQUEEZE), 0.1736(SQUEEZE) \\
\hline
\end{tabular}

[a] $R_{1}=\Sigma|| F_{\mathrm{o}}|-| F_{\mathrm{c}}|| / \Sigma\left|F_{\mathrm{o}}\right| ;[\mathrm{b}] w R_{2}=\left[\Sigma w\left(F_{\mathrm{o}}{ }^{2}-{F_{\mathrm{c}}}^{2}\right)^{2} / \Sigma w\left(F_{\mathrm{o}}{ }^{2}\right)^{2}\right]^{1 / 2}$.

\section{Results and Discussion}

\subsection{Synthesis Conditions}

The development of a suitable synthetic method is of a primary importance in chemistry. Solvothermal method is widely used in the construction of PCPs, and there are many factors that could help to manipulate the structure of the product. It is surprising that there are rare cases of $\mathrm{H}_{2}$ bpdc ligands which coordinate to form homometallic frameworks [29] with twelfth group (IIB) metal ions with the capability to form complexes. We have reported two complexes with group IIA metal ions- $\mathrm{Ca}(\mathrm{bpdc})(\mathrm{DMF})_{2}\left(\mathrm{H}_{2} \mathrm{O}\right)_{2}$ and $\mathrm{Mg}(\mathrm{bpdc})\left(\mathrm{H}_{2} \mathrm{O}\right)_{3}$ - which were obtained from DMF solution using solvothermal conditions [41]. Fortunately, while replacing the metal ions and adjusting the standing time before heating, three novel flexible PCPs formed with $\mathrm{H}_{2}$ bpdc ligand and cadmium/zinc ions- $\left[\mathrm{Cd}_{2}(\mathrm{bpdc})_{2}\right](\mathrm{DMF})_{3}\left(\mathrm{H}_{2} \mathrm{O}\right)(\mathbf{1})$ and $[\mathrm{M}(\mathrm{bpdc})](\mathrm{DMF})\left(\mathrm{H}_{2} \mathrm{O}\right)(\mathrm{M}=\mathrm{Cd}(\mathbf{2}), \mathrm{Zn}(\mathbf{3}))$-were produced and characterized. To our best knowledge, this is the first time when the flexible frameworks composed of cadmium ions and $\mathrm{bpdc}^{2-}$ ligands are reported. It should be mentioned that the standing time for a week is necessary since if the mixture of reactants is placed directly at high temperature, the product is 
a non-crystalline solid. Because of the different properties shown between cadmium complexes and zinc complex, the mercury complex has been attempted in a similar way, but unfortunately no similar porous framework could be obtained.

\subsection{Crystal Structures of $\mathbf{1 - 3}$}

Single crystal X-ray diffraction analysis revealed that complex 1 crystallizes in the space group $P 2_{1} / c$ and is a three-dimensional coordination polymer with large pores in the structure. In the asymmetric unit, there are two independent $\mathrm{Cd}^{2+}$ atoms, two bpdc ${ }^{2-}$ ligands, three DMF, and one $\mathrm{H}_{2} \mathrm{O}$ guest molecule. The $\mathrm{Cd} 1$ and $\mathrm{Cd} 2$ atoms are both in distorted octahedral geometry formed by four oxygen atoms from four carboxylate groups and two nitrogen atoms of the bipyridyl group $\left(\Sigma_{\mathrm{Cd} 1}=97.5^{\circ}, \Sigma_{\mathrm{Cd} 2}=112.6^{\circ}\right)$ [42] (Figure 2a), and two Cd atoms form a wheel dinuclear unit, $\mathrm{Cd}_{2}(\mathrm{COO})_{4}$. The bpdc ${ }^{2-}$ ligand, coordinating to five $\mathrm{Cd}$ atoms, is a T-shaped connector (type a) which is of two types $(\operatorname{bpdc}(\mathrm{N} 1,2)$ and $\operatorname{bpdc}(\mathrm{N} 3,4))$, chelating atoms $\mathrm{Cd} 1$ and $\mathrm{Cd} 2$ atoms, respectively. The bpdc $(\mathrm{N} 1,2)$ ligands as type $\mathrm{f}$ connect three $\mathrm{Cd} 1$ atoms into wavy 2D layers (Figure S1) which are further linked with the adjacent wavy layers composed of bpdc(N3,4) ligands and $\mathrm{Cd} 2$ atoms via the dinuclear units into 3D porous coordination framework (Figure $2 b$ ), which exhibits four types of open channels along the $a$-axis, $c$-axis, [101], and [111] directions (Figure S2).

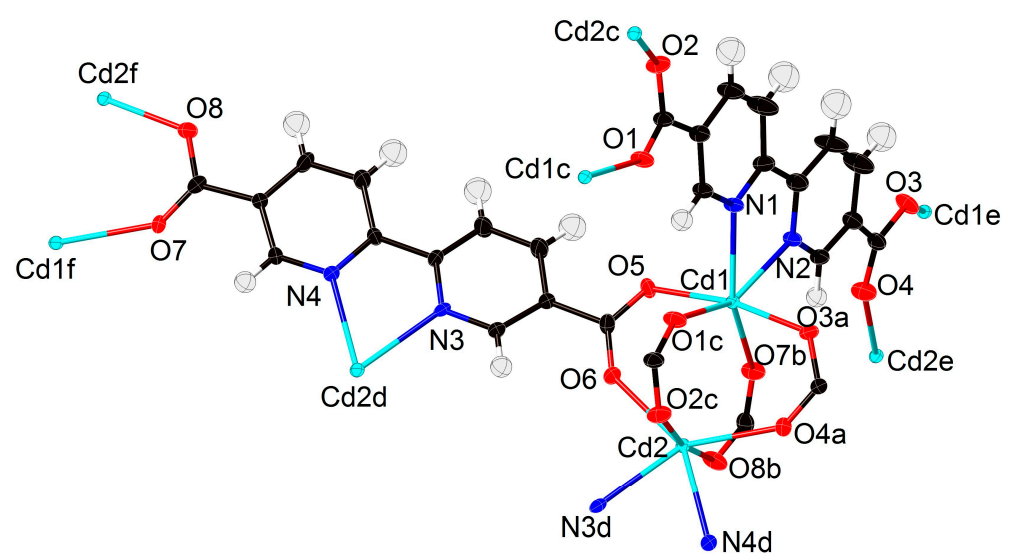

(a)

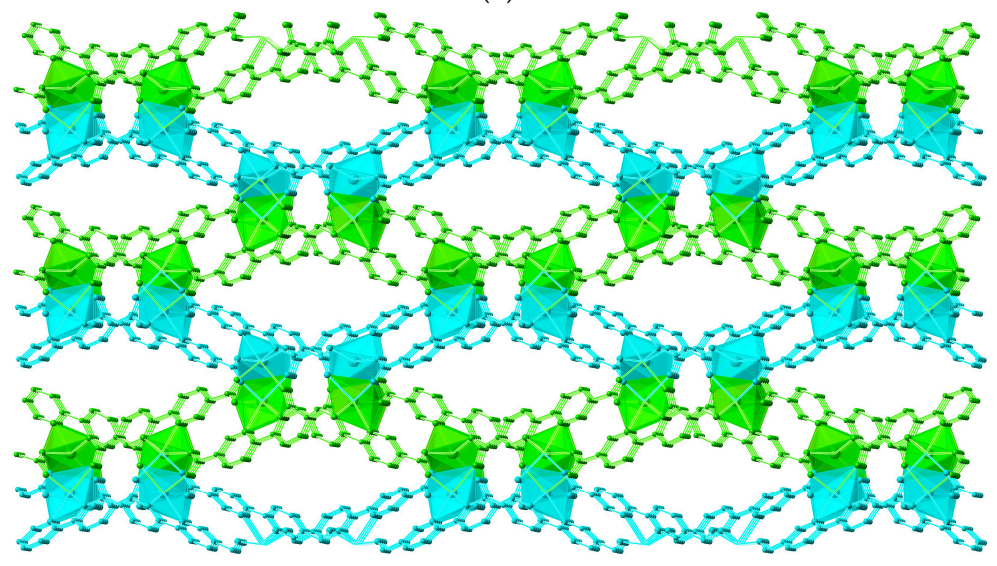

(b)

Figure 2. Cont. 


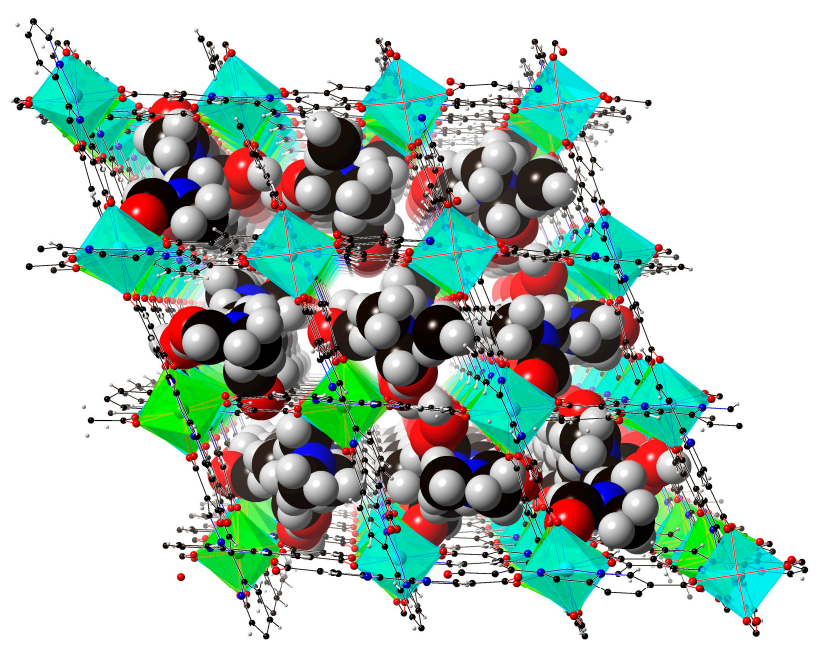

(c)

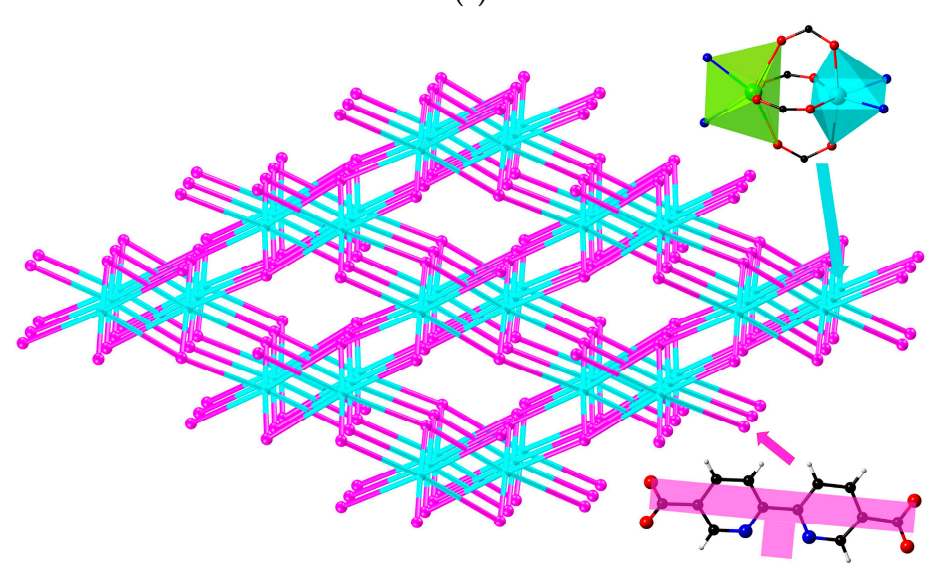

(d)

Figure 2. (a) Coordination environments of $\mathrm{Cd}^{2+}$ atoms and $\mathrm{bpdc}^{2-}$ ligand in complex 1; (b) Polyhedral view (green and cyan polyhedrons represent the $\mathrm{Cd} 1$ and $\mathrm{Cd} 2$, respectively) for 3D framework composed of two infinite $\mathrm{Cd}(\mathrm{bpdc})$ plane along c-axis; (c) The guest molecules of DMF and $\mathrm{H}_{2} \mathrm{O}$ situated in the framework along the [101] direction; (d) The $(6,3)$ connected topology network in complex 1.

From PLATON calculation [43], the total void volume for filling in potential solvent is about $1886 \AA^{3}$, which is $49.8 \%$ of the unit cell volume for the porous structure. Among the described types of channels, the biggest one is a quadrangled open channel with the dimensions $3.5 \times 11.9 \AA$ in herringbone pattern stacking along [101] direction. Three DMF molecules and one water molecule, arranged in a line along that channel (Figure 2c), are retained via hydrogen bonding interactions $\left(d_{\mathrm{C}-\mathrm{H} \ldots \mathrm{O}}=2.04-2.66 \AA \AA \mathrm{A}, \angle \mathrm{C}-\mathrm{H} \ldots \mathrm{O}=114.0^{\circ}-164.3^{\circ}\right)$ (Figure S3). While the dinuclear units $\mathrm{Cd}_{2}(\mathrm{COO})_{4}$ are considered as six-connected nodes, the bpdc ${ }^{2-}$ ligands can be regarded as three-connected T-shaped nodes, thus the 3D framework structure of complex 1 can be simplified into a $(6,3)$ connected ant topological network with the Schläfli symbol of $\left\{4^{4} \cdot 6^{2} \cdot 8^{8} \cdot 10\right\}\left\{4^{2} \cdot 6\right\}$ (Figure 2d). To the best of our knowledge, complex 1 is the first homometallic structure composed of $\mathrm{Cd}^{2+}$ ions and bpdc ${ }^{2-}$ ligands.

The frameworks of complexes $\mathbf{2}$ and $\mathbf{3}$ are similar to that of complex 1, whereas a similar network, [Mn(bpydc)].DMA, has been reported by Liu et al. [25]. Differences of the structural compositions of 1-3 are the numbers of guest molecules and the metal ion centers. Interestingly, for $\mathbf{2}$ and $\mathbf{3}$, the crystallographic data show that the structures crystallize in a higher symmetry space group Fddd, resulting in the asymmetric unit contents reduced by half (Figure S4). Furthermore, the frameworks of $\mathbf{2}$ and $\mathbf{3}$ became more square, although they are composed of similar dinuclear units and can be 
simplified into the same ant topology. Looking into structures of 1-3 (Figure 3), the size of metal ions might affect the construction of the frameworks. For the first two complexes, coordination bond lengths $(\mathrm{Cd}-\mathrm{O}=2.166(4)-2.446(4) \AA, \mathrm{Cd}-\mathrm{N}=2.372(4)-2.396(3) \AA)$ are longer than those of complex $3(\mathrm{Zn}-\mathrm{O}=1.947(4)-2.384(3) \AA, \mathrm{Zn}-\mathrm{N}=2.208(4) \AA)$, and the distortions of structures 1 and 2 are smaller than that of 3 (Table S1). Besides that, the different distortions, caused by different hydrogen bonding interactions ( $16-\mathrm{H} 16 \mathrm{~A} \ldots \mathrm{O} 1 \mathrm{~W}=2.62 \AA)$, in two pyridyl planes in complex 1 affect the symmetry of the dinuclear unit (Table S2). Therefore, the dihedral angles between the bipyridyl planes, $65.9^{\circ}, 75.3^{\circ}$, and $78.3^{\circ}$, respectively, for 1-3 mainly result in the different distortions of the 3D coordination frameworks.

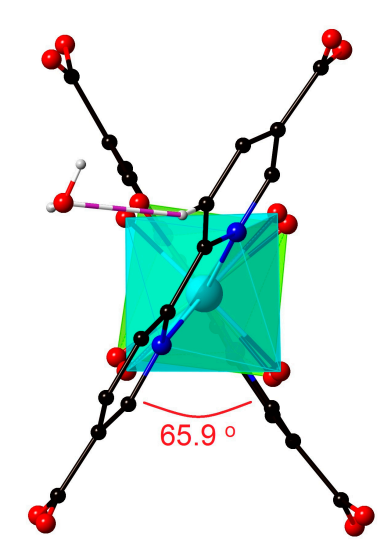

(a)

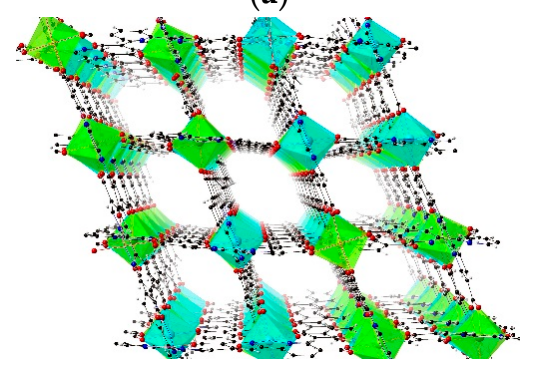

(d)

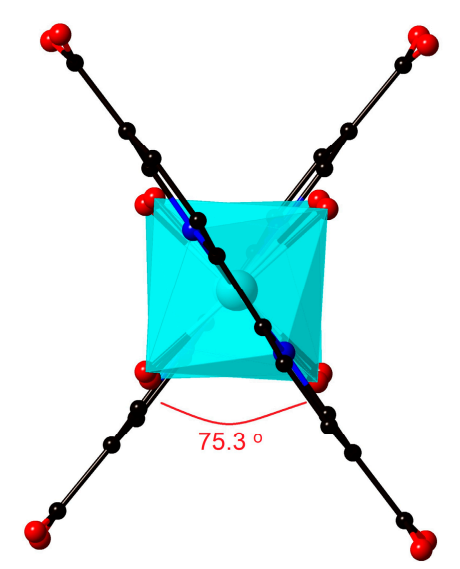

(b)

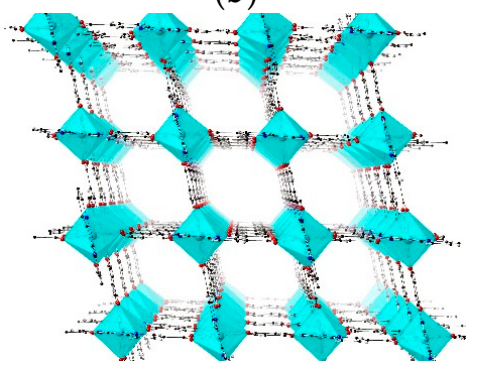

(e)

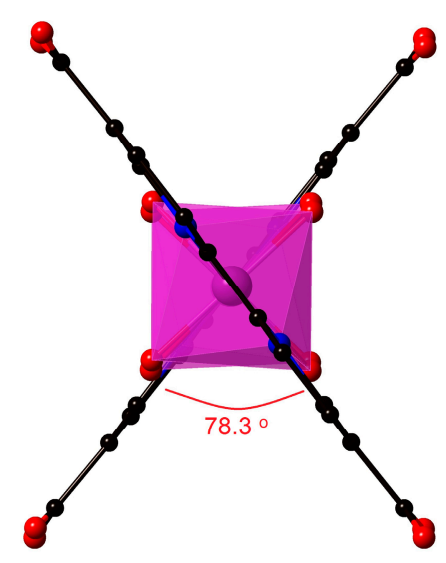

(c)

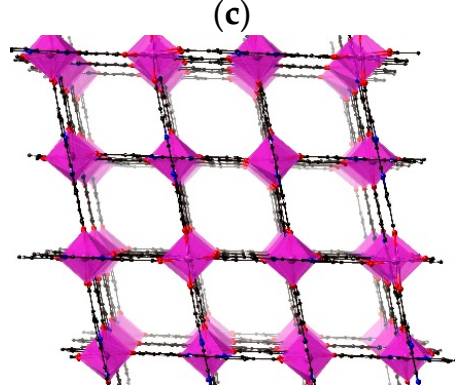

(f)

Figure 3. The difference in dihedral angles in the dinuclear units for $\mathbf{1}(\mathbf{a}), \mathbf{2}(\mathbf{b})$, and $\mathbf{3}$ (c) between the bipyridyl planes resulting in the different distortions of the 3D coordination frameworks, respectively (1 (d), 2 (e), and 3 (f)). The hydrogen bonding interaction in (a) impels the different distortions of two pyridyl planes.

\subsection{IR Spectra and TG Measurements}

As the solvent molecules in complexes 2 and 3 could not be found from single-crystal X-ray diffraction data, the composition was confirmed via elemental analysis, IR (Figure 4a), and TG data (Figure $4 \mathrm{~b}-\mathrm{d}$ ). IR spectra show that the absorption bands of $\mathrm{COO}^{-}$and bipyridyl groups are 1607 and $1396 \mathrm{~cm}^{-1}$, and 1378,848 , and $779 \mathrm{~cm}^{-1}$ respectively. The peaks at $1643,1170,1132$, and $1034 \mathrm{~cm}^{-1}$ correspond to those of DMF molecules [44]. All TG data of complexes were measured from room temperature to $700{ }^{\circ} \mathrm{C}$ under nitrogen atmosphere heated at a rate of $10^{\circ} \mathrm{C} / \mathrm{min}$. For 1 , a weight loss of $26.0 \%$ from beginning to $140{ }^{\circ} \mathrm{C}$ corresponds to the loss of three DMF and one water molecules per formula unit (calc. 25.1\%), which ensures that the formula obtained from X-ray diffraction is correct. After a long plateau, a large weight loss occurs from $320{ }^{\circ} \mathrm{C}$ to $500{ }^{\circ} \mathrm{C}$ in accordance with the decomposition of the organic ligands in the framework (found $48.5 \%$, calc. 51.1\%). For 2 and 3 , the similar TG curves show that the weight loss from room temperature to $150{ }^{\circ} \mathrm{C}$ or $170{ }^{\circ} \mathrm{C}$ would correspond to the loss of one DMF and one water molecules in the formula, respectively (for 2 , found 
$20.5 \%$, calc. $20.4 \%$; for 3 , found $25.2 \%$, calc. $23.7 \%$ ). Since the mass loss of samples 2 and 3 continued after $700{ }^{\circ} \mathrm{C}$, the PXRD of the remaining sample show that the peaks are corresponding to that of $\mathrm{CdO}$ and $\mathrm{ZnO}$, respectively (Figure S5).

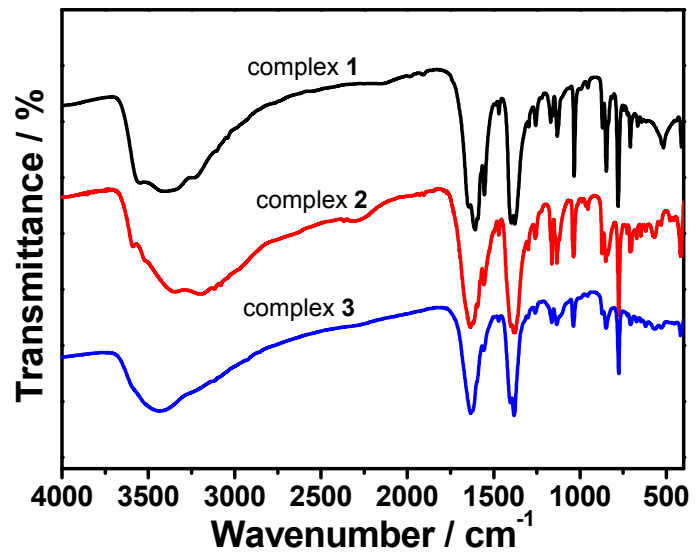

(a)

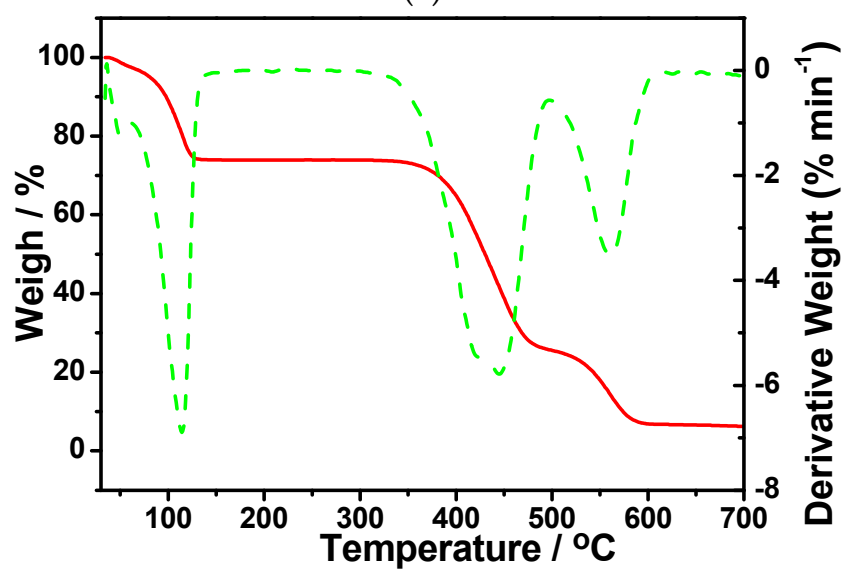

(b)

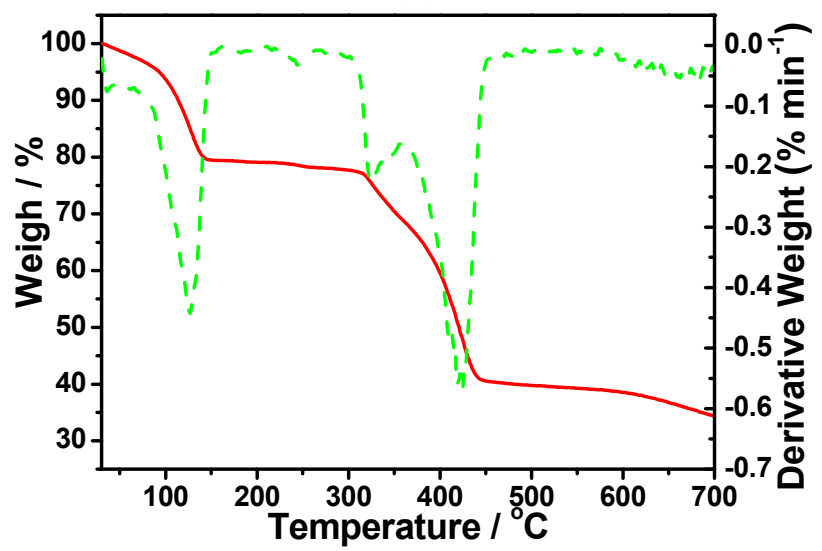

(c)

Figure 4. Cont. 


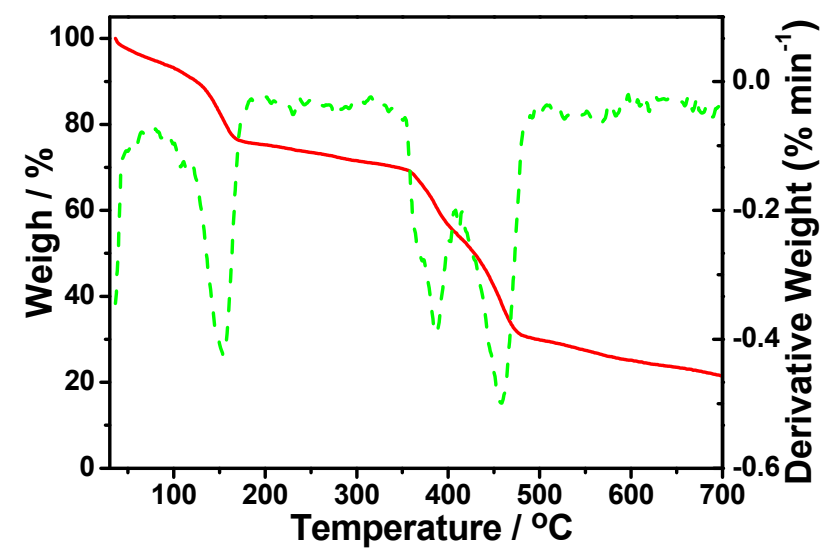

(d)

Figure 4. (a) IR spectra of 1-3. The thermogravimetric data and DTG analysis for $\mathbf{1}$ (b), 2 (c), and 3 (d).

\subsection{Stabilities and Structure Transformation}

Because complexes 1-3 show long plateaus after the solvent molecules lost in TG data, the desolvated complexes were characterized with PXRD. Interestingly, the peaks of three desolvated samples - which are different from that of 1-3 with guest molecules-turned into a similar pattern and became broader which might be due to the distortion of the porous frameworks (Figure S6). This means that the crystallinities of all the frameworks could not be sustained, and unfortunately, the structures could not be retrieved through the powder diffraction data since the crystallinities were not good enough. Adsorption of $\mathrm{N}_{2}$ gas at $77 \mathrm{~K}$ for activated samples of $\mathbf{1}$ were measured and showed no adsorption capacity (Figure S7). On the other hand, the difference between $\mathbf{1}$ and $\mathbf{2}$ indicated that the possibility might exist that complex $\mathbf{1}$ could change into complex $\mathbf{2}$. Herein, after crystals of $\mathbf{1}$ were immersed in the DMF and $\mathrm{H}_{2} \mathrm{O}$ equimolar mixture for one week, the crystal structure changed into 2, and vice versa, which was confirmed by PXRD (Figure 5, I, II, III). However, for complex 3, it could not absorb more DMF molecules into the pores even if the dehydrated DMF was used. This phenomenon could be ascribed to the different metal properties and host-guest interactions [45].

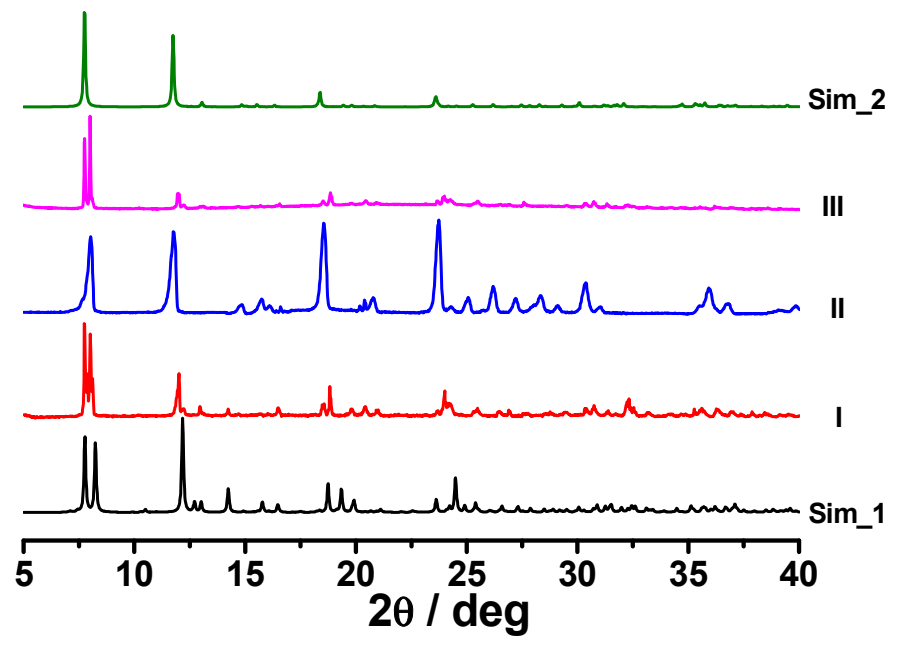

Figure 5. The powder XRD (PXRD) patterns showing the structural transformations of 1 : (I) is the original sample; (II) is the sample immersed in DMF: $\mathrm{H}_{2} \mathrm{O}$ (1:1) for one week; (III) is sample II after being immersed back in DMF for one week. Sim_1 and Sim_2 represent the simulation patterns for $\mathbf{1}$ and 2 , respectively. 


\subsection{Luminescent Properties}

The solid-state photoluminescence properties of complexes 1-3 have been studied at room temperature. It is well known that the luminescent properties of $\mathrm{d}^{10}$ metal complexes could be affected by the coordination modes of organic ligands and/or the guest molecules [46]. Compared to the emission peaks (455 and $547 \mathrm{~nm}$ ) of the $\mathrm{H}_{2}$ bpdc [41], the emission peaks of 1 and $2-417 \mathrm{~nm}$ and $447 \mathrm{~nm}$, respectively-are hypochromatically shifted whereas that of $3(467 \mathrm{~nm})$ is bathochromically shifted (Figure 6). The emissions could be attributed to the $\pi-\pi^{*}$ transition within the bipyridyl ligands, and the different shifts between cadmium complexes and zinc complex might be the metal ion effects in the coordination structure, because the energy levels are different. It is noticed that the emission band of 1 at $417 \mathrm{~nm}$ is obviously red shifting to the emission band of 2 at $447 \mathrm{~nm}$, which might be ascribed to the different distortion of two pyridyl rings of the bpdc ${ }^{2-}$ ligands and the effect of guest molecules [47]. Furthermore, the luminescent properties of desolvated samples of 1-3 show similar emission peaks at $460 \mathrm{~nm}$ (Figure S8). These complexes might be potentially used as a probe.

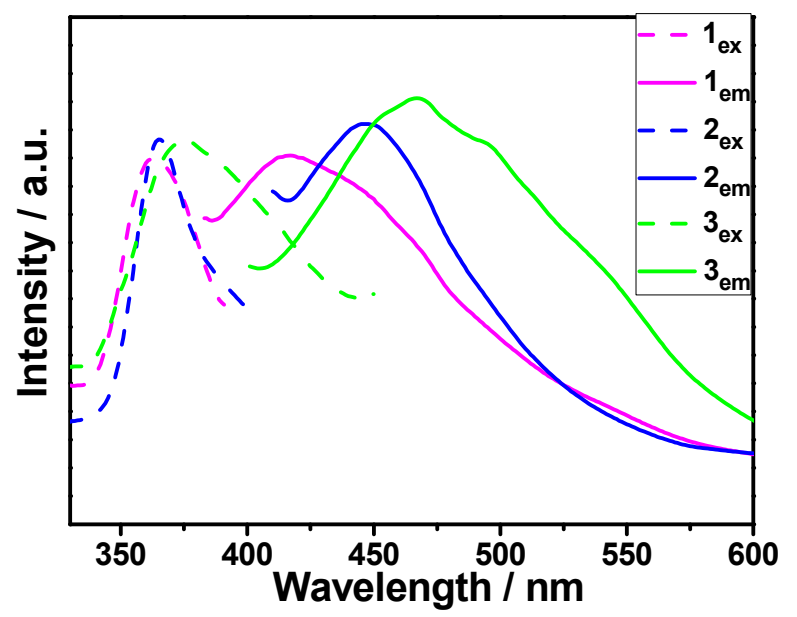

Figure 6. Luminescent properties of 1-3.

\section{Conclusions}

In summary, three novel $\mathrm{d}^{10}$ metal porous coordination polymers have been isolated with T-shaped connecting linkers and fully characterized. Here, complexes $\mathbf{1}$ and $\mathbf{2}$ with large porous channels exhibited structural transformation during the desorption/adsorption of DMF molecules, and further showed the shift of emission peaks which imply their potential use as a probe. However, the zinc complex 3 could not adsorb DMF molecules to change the structure and exhibited blue emission in fluorescence. This work introduces a special synthetic method and idea in crystallizing and tuning the pore structures, and could open the way to constructing novel complexes.

Supplementary Materials: The following are available online at www.mdpi.com/2073-4352/7/10/311/s1, Scheme S1: Coordination modes displayed by $\mathrm{H}_{2}$ bpdc ligand in metal complexes, as retrieved from the Cambridge Structural Database (CSD version 5.38, updated to Feb 2017); Figure S1: The wavy 2D layer structure of Cd1bpdc(N1,2); Figure S2: View of the 3D porous structure of 1 from direction on $a$-axis (a), $c$-axis (b), (101) (c) and (111) (d); Figure S3: The hydrogen bonding interactions (multi-color bonds) for the DMF and $\mathrm{H}_{2} \mathrm{O}$ molecules in complex 1; Figure S4: (a) The coordination environments of metal atoms and bpdc ${ }^{2-}$ ligand and (b) the ant topological network for 2 and 3. (cyan balls and purple balls represent dinuclear units and bpdc ${ }^{2-}$ ligands respectively); Figure S5: The PXRD patterns for the rest samples of 2 (a) and $\mathbf{3}$ (b) after TGA analysis, which corresponded to the patterns of $\mathrm{CdO}$ (monteponite, syn) and ZnO (Zincite, syn) respectively; Figure S6: The XPRD patterns for desolvated samples of 1-3; Figure S7: The N2 adsorption data at $77 \mathrm{~K}$ of the activated samples of 1; Figure S8: The luminescent properties for active samples of two metal complexes excited at $363 \mathrm{~nm}$; Table S1: Selected bond lengths $(\AA)$ and angles $\left(^{\circ}\right)$ for 1-3; Table S2: Selected Hydrogen bond lengths $(\AA)$ and angles $\left(^{\circ}\right)$ for 1. Supporting figures: adsorption data and PXRD patterns. X-ray crystallographic file in CIF format (CCDC: 1548356, 1548357, 1548358). Supplementary data to this article can be found online at http://dx.doi.org/. 
Acknowledgments: This work was supported by the NSFC (Grant No. 21401058) and Yong Innovative Talents Program of Guangdong (2014KQNCX058).

Author Contributions: Ying-Yi Song designed and performed the experiments; Hui-Ming Du and Meng-Meng Hao analyzed the data; Yong-Cong Ou and Jian-Zhong Wu wrote the paper.

Conflicts of Interest: The authors declare no competing financial interests.

\section{References}

1. Kim, H.; Yang, S.; Rao, S.R.; Narayanan, S.; Kapustin, E.A.; Furukawa, H.; Umans, A.S.; Yaghi, O.M.; Wang, E.N. Water harvesting from air with metal-organic frameworks powered by natural sunlight. Science 2017, 356, 430-434. [CrossRef] [PubMed]

2. Li, B.; Wen, H.-M.; Cui, Y.; Zhou, W.; Qian, G.; Chen, B. Emerging multifunctional metal-organic framework materials. Adv. Mater. 2016, 28, 8819-8860. [CrossRef] [PubMed]

3. Li, J.-R.; Kuppler, R.J.; Zhou, H.-C. Selective gas adsorption and separation in metal-organic frameworks. Chem. Soc. Rev. 2009, 38, 1477-1504. [CrossRef] [PubMed]

4. $\quad$ Fan, C.B.; Gong, L.L.; Huang, L.; Luo, F.; Krishna, R.; Yi, X.F.; Zheng, A.M.; Zhang, L.; Pu, S.Z.; Feng, X.F.; et al. Significant enhancement of $\mathrm{C} 2 \mathrm{H} 2 / \mathrm{C} 2 \mathrm{H} 4$ separation by a photochromic diarylethene unit: A temperatureand light-responsive separation switch. Angew. Chem. Int. Ed. 2017, 56, 7900-7906. [CrossRef] [PubMed]

5. Zhao, S.-N.; Song, X.-Z.; Song, S.-Y.; Zhang, H.-J. Highly efficient heterogeneous catalytic materials derived from metalorganic framework supports/precursors. Coord. Chem. Rev. 2017, 337, 80-96. [CrossRef]

6. Liu, J.; Chen, L.; Cui, H.; Zhang, J.; Zhang, L.; Su, C.-Y. Applications of metal-organic frameworks in heterogeneous supramolecular catalysis. Chem. Soc. Rev. 2014, 43, 6011-6061. [CrossRef] [PubMed]

7. Zhao, M.; Ou, S.; Wu, C.-D. Porous metal-organic frameworks for heterogeneous biomimetic catalysis. Acc. Chem. Res. 2014, 47, 1199-1207. [CrossRef] [PubMed]

8. Farrusseng, D.; Aguado, S.; Pinel, C. Metal-organic frameworks: Opportunities for catalysis. Angew. Chem. Int. Ed. 2009, 48, 7502-7513. [CrossRef] [PubMed]

9. Ni, Z.-P.; Liu, J.-L.; Hoque, M.N.; Liu, W.; Li, J.-Y.; Chen, Y.-C.; Tong, M.-L. Recent advances in guest effects on spin-crossover behavior in Hofmann-type metal-organic frameworks. Coord. Chem. Rev. 2017, 335, $28-43$. [CrossRef]

10. Coronado, E.; Espallargas, G.M. Dynamic magnetic MOFs. Chem. Soc. Rev. 2013, 42, 1525-1539. [CrossRef] [PubMed]

11. Lin, R.-B.; Liu, S.-Y.; Ye, J.-W.; Li, X.-Y.; Zhang, J.-P. Photoluminescent metal-organic frameworks for gas sensing. Adv. Sci. 2016, 3, 1500434-1500453. [CrossRef] [PubMed]

12. Wales, D.J.; Grand, J.; Ting, V.P.; Burke, R.D.; Edler, K.J.; Bowen, C.R.; Mintova, S.; Burrows, A.D. Gas sensing using porous materials for automotive applications. Chem. Soc. Rev. 2015, 44, 4290-4321. [CrossRef] [PubMed]

13. Hu, Z.; Deiberta, B.J.; Li, J. Luminescent metal-organic frameworks for chemical sensing and explosive detection Chem. Soc. Rev. 2014, 43, 5815-5840. [CrossRef] [PubMed]

14. Wyszogrodzka, G.; Marszałek, B.; Gil, B.; Dorożyński, P. Metal-organic frameworks: Mechanisms of antibacterial action and potential applications. Drug Discov. Today 2016, 21, 1009-1018. [CrossRef] [PubMed]

15. Rocca, J.D.; Liu, D.; Lin, W. Nanoscale metal-organic frameworks for biomedical imaging and drug delivery. Acc. Chem. Res. 2011, 44, 957-968. [CrossRef] [PubMed]

16. Horike, S.; Umeyama, D.; Kitagawa, S. Ion conductivity and transport by porous coordination polymers and metal-organic frameworks. Acc. Chem. Res. 2013, 46, 2376-2384. [CrossRef] [PubMed]

17. Schneemann, A.; Bon, V.; Schwedler, I.; Senkovska, I.; Kaskel, S.; Fischer, R.A. Flexible metal-organic rameworks. Chem. Soc. Rev. 2014, 43, 6062-6069. [CrossRef] [PubMed]

18. Lin, Z.-J.; Lv, J.; Hong, M.; Cao, R. Metal-organic frameworks based on flexible ligands (FL-MOFs): Structures and applications. Chem. Soc. Rev. 2014, 43, 5867-5895. [CrossRef] [PubMed]

19. Ou, Y.-C.; Gao, X.; Zhou, Y.; Chen, Y.-C.; Wang, L.-F.; Wu, J.-Z.; Tong, M.-L. Magnetic properties and photoluminescence of lanthanide coordination polymers constructed with conformation-flexible cyclohexane-tetracarboxylate ligands. Cryst. Growth Des. 2016, 16, 946-952. [CrossRef]

20. Liu, G.; Zeller, M.; Su, K.; Pang, J.; Ju, Z.; Yuan, D.; Hong, M. Controlled orthogonal self-assembly of heterometal-decorated coordination cages. Chem. Eur. J. 2016, 22, 17345-17350. [CrossRef] [PubMed] 
21. Gonzalez, M.I.; Bloch, E.D.; Mason, J.A.; Teat, S.J.; Long, J.R. Single-crystal-to-single-crystal metalation of a metal-organic framework: A route toward structurally well-defined catalysts. Inorg. Chem. 2015, 54, 2995-3005. [CrossRef] [PubMed]

22. Zhang, S.; Li, L.; Zhao, S.; Sun, Z.; Luo, J. Construction of interpenetrated ruthenium metal-organic frameworks as stable photocatalysts for $\mathrm{CO}_{2}$ reduction. Inorg. Chem. 2015, 54, 8375-8379. [CrossRef] [PubMed]

23. Blake, A.J.; Champness, N.R.; Easun, T.L.; Allan, D.R.; Nowell, H.; George, M.W.; Jia, J.; Sun, X.-Z. Photoreactivity examined through incorporation in metal-organic frameworks. Nat. Chem. 2010, 2, 688-694. [CrossRef] [PubMed]

24. Bon, V.; Kavoosi, N.; Senkovska, I.; Müller, P.; Schaber, J.; Wallacher, D.; Többens, D.M.; Mueller, U.; Kaskel, S. Tuning the flexibility in MOFs by SBU functionalization. Dalton Trans. 2016, 45, 4407-4415. [CrossRef] [PubMed]

25. Wang, J.; Jing, X.; Cao, Y.; Li, G.; Huo, Q.; Liu, Y. Structural diversity and magnetic properties of three metal-organic frameworks assembled from a T-shaped linker. CrystEngComm 2015, 17, 604-611. [CrossRef]

26. Wang, J.; Luo, J.; Zhao, J.; Li, D.-S.; Li, G.; Huo, Q.; Liu, Y. Assembly of two flexible metal-organic frameworks with stepwise gas adsorption and highly selective CO2 adsorption. Cryst. Growth Des. 2014, 14, 2375-2380. [CrossRef]

27. Shen, L.; Gray, D.; Masel, R.I.; Girolami, G.S. Synthesis and characterization of a zinc metal-organic framework with chiral nano-pores. CrystEngComm 2012, 14, 5145-5147. [CrossRef]

28. Gustafsson, M.; Su, J.; Yue, H.; Yao, Q.; Zou, X. A family of flexible lanthanide bipyridinedicarboxylate metal-organic frameworks showing reversible single-crystal to single-crystal transformations. Cryst. Growth Des. 2012, 12, 3243-3249. [CrossRef]

29. Huh, S.; Jung, S.; Kim, Y.; Kim, S.-J.; Park, S. Two-dimensional metal-organic frameworks with blue luminescence. Dalton Trans. 2010, 39, 1261-1265. [CrossRef] [PubMed]

30. Wang, J.; Luo, J.; Zhi, B.; Li, G.; Huo, Q.; Liu, Y. Anion-templated assembly of three indium-organic frameworks with diverse topologies. CrystEngComm 2014, 16, 9810-9816. [CrossRef]

31. Zhao, B.; Fang, M.; Shi, P.-F.; Jiang, D.-X.; Chang, P.; Shi, W. A series of 3d-4f heterometallic three-dimensional coordination polymers: Syntheses, structures and magnetic properties. Dalton Trans. 2012, 41, 6820-6826.

32. Liu, D.; Huxford, R.C.; Lin, W. Phosphorescent nanoscale coordination polymers as contrast agents for optical imaging. Angew. Chem. Int. Ed. 2011, 50, 3696-3700. [CrossRef] [PubMed]

33. Wen, G.-X.; Wang, J.-F.; Wu, X.-Q.; Pan, L.-Q.; Li, D.-S. One novel near-infrared ytterbium metal-organic framework based on an unprecedented $[\mathrm{Yb} 6(\mu 2-\mathrm{OH}) 2(\mu 3-\mathrm{OH}) 6] 10+$ cluster. Inorg. Chem. Commun. 2016, 70, 111-114. [CrossRef]

34. Huang, S.-L.; Jia, A.-Q.; Jin, G.-X. Pd(diimine)Cl2 embedded heterometallic compounds with porous structures as efficient heterogeneous catalysts. Chem. Commun. 2013, 49, 2403-2405. [CrossRef] [PubMed]

35. Ayhan, O.; Malaestean, I.L.; Ellern, A.; van Leusen, J.; Baca, S.G.; Kogerler, P. Assembly of cerium(III) 2,2'-bipyridine-5,5'-dicarboxylate-based metal-organic frameworks by solvent tuning. Cryst. Growth Des. 2014, 14, 3541-3548. [CrossRef]

36. Lin, X.; Hong, Y.; Zhang, C.; Huang, R.; Wang, C.; Lin, W. Pre-concentration and energy transfer enable the efficient luminescence sensing of transition metal ions by metal-organic frameworks. Chem. Commun. 2015, 51, 16996-16999. [CrossRef] [PubMed]

37. Zhao, R.; Mei, L.; Wang, L.; Chai, Z.-F.; Shi, W.-Q. Copper/zinc-directed heterometallic uranyl-organic polycatenating frameworks: Synthesis, characterization, and anion-dependent structural regulation. Inorg. Chem. 2016, 55, 10125-10134. [CrossRef] [PubMed]

38. Allen, F.H.; Taylor, R. Research applications of the Cambridge Structural Database (CSD). Chem. Soc. Rev. 2004, 33, 463-475. [CrossRef] [PubMed]

39. Sheldrick, G.M. Crystal structure refinement with SHELXL. Acta Cryst. 2015, C71, 3-8.

40. Van Der Sluis, P.; Spek, A.L. BYPASS: An effective method for the refinement of crystal structures containing disordered solvent regions. Acta Cryst. 1990, A46, 194-201. [CrossRef]

41. Ou, Y.-C.; Zhong, J.-X.; Song, Y.-Y.; Zhu, L.-L.; Wu, J.-Z. Two 1D chain structures derived from alkaline-earth metal complexes and 2,2'-bipyridine-5,5'-dicarboxylate ligand: Syntheses, crystal structures and luminescent properties. Chin. J. Inorg. Chem. 2016, 32, 738-744. 
42. Guionneau, P.; Marchivie, M.; Bravic, G.; Létard, J.F.; Chasseau, D. Co (II) molecular complexes as a reference for the spin crossover in Fe (II) analogues. Mater. Chem. 2002, 12, 2546-2551. [CrossRef]

43. Spek, A.L. Single-crystal structure validation with the program PLATON. J. Appl. Crystallogr. 2003, 36, 7-13. [CrossRef]

44. Nakamoto, K. Infrared and Raman Spectra of Inorganic and Coordination Compounds, 6th ed.; John Wiley and Sons, Inc.: Hoboken, NJ, USA, 2009.

45. Klein, N.; Hoffmann, H.C.; Cadiau, A.; Getzschmann, J.; Lohe, M.R.; Paasch, S.; Heydenreich, T.; Adil, K.; Senkovska, I.; Brunner, E.; et al. Structural flexibility and intrinsic dynamics in the M2(2,6-ndc)2(dabco) $(\mathrm{M}=\mathrm{Ni}, \mathrm{Cu}, \mathrm{Co}, \mathrm{Zn})$ metal-organic frameworks. J. Mater. Chem. 2012, 22, 10303-10312. [CrossRef]

46. Kreno, L.E.; Leong, K.; Farha, O.K.; Allendorf, M.; Van Duyne, R.P.; Hupp, J.T. Metal-Organic Framework Materials as Chemical Sensors. Chem. Rev. 2012, 112, 1105-1125. [CrossRef] [PubMed]

47. Allendorf, M.D.; Bauer, C.A.; Bhakta, R.K.; Houk, R.J.T. Luminescent metal-organic frameworks. Chem. Soc. Rev. 2009, 38, 1330-1352. [CrossRef] [PubMed]

(C) 2017 by the authors. Licensee MDPI, Basel, Switzerland. This article is an open access article distributed under the terms and conditions of the Creative Commons Attribution (CC BY) license (http:/ / creativecommons.org/licenses/by/4.0/). 